\title{
Forced Electrocodeposition of Silica Particles into Nickel Matrix by Horizontal Impinging Jet Cell
}

\author{
Désiré M. K. Abro', Pierre Jean Marie Richard Dable², Véronique Amstutz³, \\ Edith Kouassi Kwa-Koffi ${ }^{1}$, Hubert Girault ${ }^{3}$
}

${ }^{1}$ Faculté des Sciences des Structures de la Matière et de Technologie, Université Félix HOUPHOUET-BOIGNY, Abidjan, Côte d'Ivoire

${ }^{2}$ Département de Génie Mécanique et Energétique, Institut National Polytechnique Félix HOUPHOUET-BOIGNY, Yamoussoukro, Côte d'ivoire

${ }^{3}$ Institut des sciences et ingénierie chimiques, Ecole Polytechnique Fédérale de Lausanne, Sion, Suisse

Email: abrodesire@hotmail.com

How to cite this paper: Abro, D.M.K., Dable, P.J.M.R., Amstutz, V., Kwa-Koffi, E.K. and Girault, H. (2017) Forced Electrocodeposition of Silica Particles into Nickel Matrix by Horizontal Impinging Jet Cell. Journal of Materials Science and Chemical Engineering, 5, 51-63.

https://doi.org/10.4236/msce.2017.52006

Received: January 6, 2017

Accepted: February 14, 2017

Published: February 17, 2017

Copyright $\odot 2017$ by authors and Scientific Research Publishing Inc. This work is licensed under the Creative Commons Attribution International License (CC BY 4.0).

http://creativecommons.org/licenses/by/4.0/

\begin{abstract}
The improvement of silica particle codeposition into a nickel electrodeposited composite coating (ECC) by a double face horizontal impinging jet cell (IJC) has been studied. The microstructure of coatings was examined by means of scanning electron microscopy performed in backscattered electron mode. The embedded particles distribution was shown to be the densest and the most uniform in laminar low flow mode and when the nozzle is at a distance of $5 \mathrm{~mm}$ close from the cathode. Excrescences observed on the composite surface are due to the wave-like flow of the jet on the cathode surface. The silica content of the nickel composite coatings was assessed by energy dispersive X-ray spectroscopy. The amount of particles embedded in the coating decreases with an increasing Reynolds number and as the nozzleto-sample distance $d$ becomes larger. A maximum rate of $4.43 \mathrm{wt} \%$ of silica has been successfully loaded at a distance $d$ equal to $5 \mathrm{~mm}$ in the $\mathrm{Ni}-\mathrm{SiO}_{2}$ composite coating.
\end{abstract}

\section{Keywords}

Electrocodeposition, Nickel-Silica, Composite Coatings, Impinging

Jet Cell, Hydrodynamics

\section{Introduction}

This Electrodeposited composite coatings (ECCs) consist of an electrodeposited metal matrix in which inert particles are embedded. ECCs are used in many en- 
gineering fields such as in automotive and aerospace industries [1] [2] because they present improved mechanical [3], corrosion resistance properties [4] [5]. The most commonly studied and used particles are silicon carbide $\mathrm{SiC}$ [6] [7] [8], silicon $\mathrm{Si}$ [9], alumina $\mathrm{Al}_{2} \mathrm{O}_{3}$ [10] [11] and silica $\mathrm{SiO}_{2}$ [12] [13]. Their use depends on the coating purpose.

Typically, electrodeposition processes are widely studied and used because this technique is inexpensive and allows production of homogeneous deposits in well-controlled conditions. Current density [6], bath agitation [14], particles load in the bath [12] and particles' size are the main parameters which control the embedment rate of the inert particles into the metal matrix. In the case of SiC, many authors reported that micro sized particles codeposit more easily than nanoparticles [15] [16] [17].

The mechanism of codeposition was early studied by Guglielmi [18], which proposed particles adsorption on the cathode before their embedment. In his approach, although the theoretical evolution of embedded particles as a function of the current presented the same trend as the experimental curves, the deviations were considerable. This was related to the fact that this description only accounted for the current density and the load of particles in the bath and disregarded the bath agitation. Then, several Guglielmi-modified models have been proposed [14] [17] [19] [20]. In particular, that of Yang et al. [21] took into account the hydrodynamic and more reliably predicted $\mathrm{SiC}$ embedment rate in a nickel-cobalt matrix through a theoretical model. However, the equations involved a number of empiric corrective factors whose physical meanings were not obvious and, moreover, the particle surface chemistry was not considered.

The chemical properties of the particle's surface play an important role in the mechanism of codeposition. In fact, hydrophilic particles codeposit more hardly than hydrophobic particles. Oxide particles such as silica usually have a hydrophilic surface [13] [22] [23]. This property originates from hydrogen bonds between silanol groups located on the particles surface and the water molecules of the plating bath [24]. A multilayer coverage of water molecules then surrounds particles. Nowak et al. [23] proved that the thickness of the water layer exceeded the thickness of the electric double layer. The particles are therefore, held away from the cathode and this prevents their codeposition.

In order to overcome this phenomenon and improve silica embedment rate, several approaches were proposed to change the particles' hydrophilicity to hydrophobicity. One of them is to convert silanol groups into siloxane through a multisteps process at high temperature and under vacuum [24]. Alternatively, Kobayashi [25] proposed a surface treatment of silica by oligodimethylsiloxane- $\alpha, \omega$-diol to turn hydrophilic silica surfaces into hydrophobic surfaces. Using this methodology, Terzieva et al. [13] achieved a copper/silica ECC containing 9 vol\% particles embedded. However, it should be noted that these physical and chemical approaches involve the use of reactors and specific equipment as well as several handling steps. They are therefore demanding in terms of materials and of time. Their scale-up is so less straightforward. Considering especially the 
mechanical and corrosion resistance properties of silica composites and their use in large-scale systems, the availability of more accessible methods such as ECCs preparation is of great importance.

The aim of this work is to modulate the hydrodynamics of the electrodeposition process in order to free the silica particles from the aqueous layer without any chemical treatment and therefore, to improve the codeposition. For this purpose, a horizontal impinging jet cell (IJC) setup, previously designed and characterized [26] has been used. The effects of the flow mode and nozzle-cathode distance on the loading rate of silica particles in an electrodeposited nickel matrix have been in particular investigated.

\section{Materials and Methods}

\subsection{Codeposition Experiments}

Nickel/silica particles $\left(\mathrm{Ni}_{-} \mathrm{SiO}_{2}\right)$ composite coatings were codeposited in a double horizontal impinging jet cell, as described and characterized elsewhere [26]. In this cell, the electrolyte driven by each nozzle located on either side splashes perpendicularly on the cathode. The electrolyte was a Watt bath. The silica particles (Sikron) are characterized by a wide distribution of diameters, which $99 \%$ is below 10 microns, as depicted in Figure 1.

The bath composition and the general electrodeposition parameters are presented in Table 1.

All chemicals were used without further purification. Sodium dodecylsulfate (SDS) is used as anionic surfactant. Ultrapure water produced by a MilliQ plus

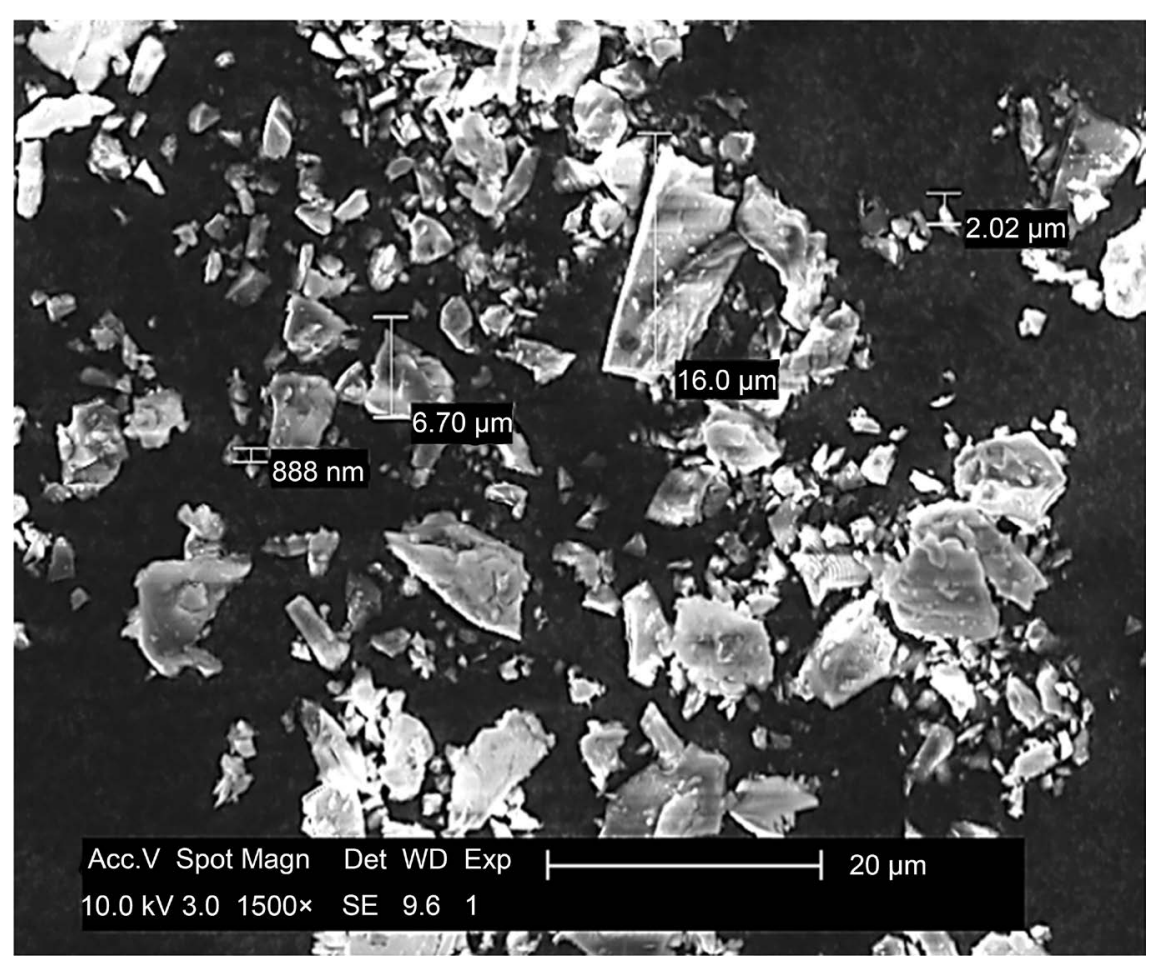

Figure 1. Scanning electron microscopy image of the silica $\mathrm{SiO}_{2}$ powder used in the preparation of the coatings. 
Table 1. Electrolyte composition and plating parametres.

\begin{tabular}{cccc}
\hline Composition & Content $(\mathrm{g} / \mathrm{L})$ & Parameters & Values \\
\hline $\mathrm{NiSO}_{4} \cdot 7 \mathrm{H}_{2} \mathrm{O}$ & 250 & $\mathrm{pH}$ & 3.7 \\
$\mathrm{NiCl}_{2} \cdot 6 \mathrm{H}_{2} \mathrm{O}$ & 90 & $\mathrm{~T}$ & $25^{\circ} \mathrm{C}$ \\
$\mathrm{H}_{3} \mathrm{BO}_{3}$ & 30 & Deposition time & $90 \mathrm{~min}$ \\
$\mathrm{SDS}$ & 0.14 & & \\
$\mathrm{SiO}_{2}$ particles & 30 & & \\
\hline
\end{tabular}

185 model from Millipore (Zug, Switzerland) was used to prepare all the solutions. The electrochemical coatings were performed using a potentiostat (AUT 71755 Metrohm, The Netherland) by chronoamperometry at $-0.9 \mathrm{~V}$ vs. $\mathrm{Ag} / \mathrm{AgCl}$.

The cathode substrate used was a carbonaceous steel XC 100 (Notz Metall) with a thickness of $0.7 \mathrm{~mm}$. The reactive surface was $S_{0}=3.42 \mathrm{~cm}^{2}$. Nickel counter-electrodes were cut into a pure nickel foil (Alfa Aeser). A hole of $6 \mathrm{~mm}$ diameter was made in the middle of each counter electrode to introduce each nozzle. The suspension was jetted on each cathode surface by two PVC tubes threaded in the nickel counter electrodes. Three nozzle-to-cathode distances $d$ were investigated: $d=5,10$ and $15 \mathrm{~mm}$. Moreover, the composite coatings were deposited for different Reynolds numbers, each corresponding to a specific hydrodynamic condition, as defined elsewhere [26]. In particular, Laminar Low Flow (LLF), Laminar High Flow (LHF) and disturbance regimes were investigated.

\subsection{Coating Characterization}

The surface morphologies of the deposited composites coatings were examined by scanning electron microscopy (SEM, Philips XL-30 FEG) in secondary electron mode (SE), while the presence of silica in coatings was highlighted in backscattered electron mode (BSE). The amount of particles loaded was estimated by means of energy-dispersive X-rays spectroscopy (EDS). The amount of particles in terms of weight percentage was determined by focusing the electron beam on three spots of $1 \mathrm{~mm}^{2}$ in the drainage area below the stagnation zone. For the cross-section examinations, the codeposited samples were cut (Accutom 50) in wafer, hot mounted (Hydropress A) in phenolic resin and polished before examination.

\section{Results and Discussions}

\subsection{Coating Microstructure}

Figure 2 depicts the SEM images of the $\mathrm{Ni}-\mathrm{SiO}_{2}$ electrodeposited coatings when $d=5 \mathrm{~mm}$ in $\operatorname{LLF}(R e=1570$, Figure 2(a) $)$ and in LHF ( $R e=5570$, Figure 2(b)).

Both composite coatings exhibit a pyramidal grain microstructure, similarly to what was reported in literature [4] [27]. It could be observed that the nickel grain size increases when passing from the LLF to the LHF hydrodynamic regimes. 

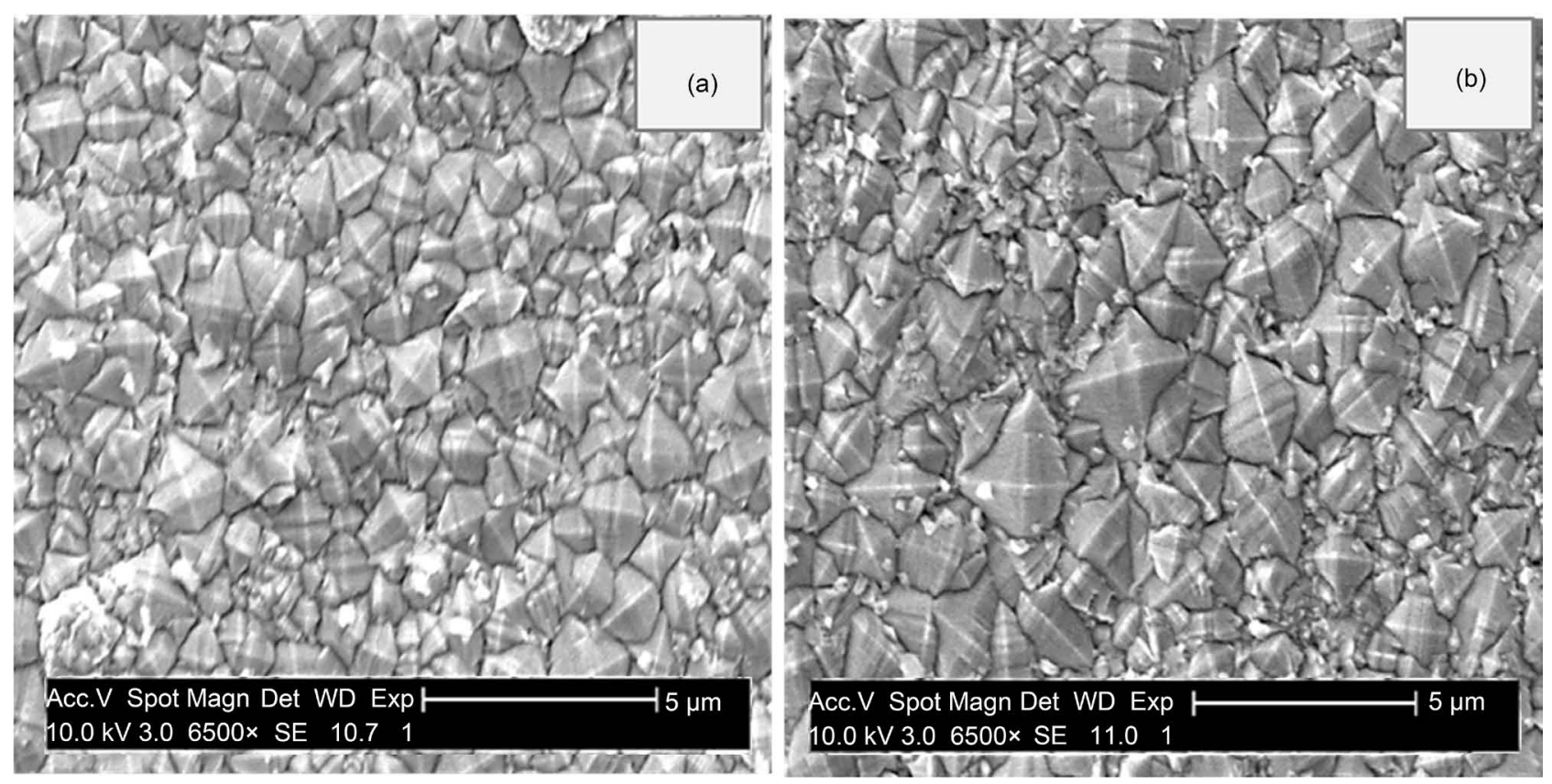

Figure 2. Scanning electron micrograph of $\mathrm{Ni}_{-} \mathrm{SiO}_{2}$ for (a) $R e=1570$ and (b) $R e=5570 . d=5 \mathrm{~mm}$.

In fact, increasing the Reynolds number increases the flow rate of the electrolyte in the system and therefore, improves the mass transport at the surface of the cathode. As a consequence, more nickel ions are available to participate to the nucleation process and the nickel grains become bigger.

The description of the jet stream on the surface of the cathode it possible to distinguish four different zones including the drainage zone located below the point of impact [26]. The observation of the drainage area surface of the coating shows a specific morphology. In fact, excrescences can be observed on the sample surface (Figure 3).

They are about 100 microns length and seem to develop in a tree shape, starting from nodules which grow into many final branches in the drainage area (Figure 3(a)). In the cross-sectional view in Figure 3(b), the profiles of the excrescences are well visible and the black spots represent the silica particles embedded into the composite coating. It can be clearly observed that into excrescences, the silica particles follow an alignment and their concentration is higher than in the basal part of the ECC.

Figure 4(a) and Figure 4(b) show excrescences developed on composite coatings in the draining flow area prepared respectively for Reynolds numbers $R e=1570$ in LLF and $R e=5570$ in LHF. The spacings between consecutive excrescences in LHF is approximately $70 \mu \mathrm{m}$ while it represents $290 \mu \mathrm{m}$ in the LLF hydrodynamic mode (in the limit of measurement errors).

The spacing between consecutive excrescences decreases as the Reynolds number increases. It is likely that the hydrodynamic regime is at the origin thereof. Excrescences formation is necessarily related to the flow on the cathode surface.

After the impact of the jet on the surface, the suspension bounces back from 

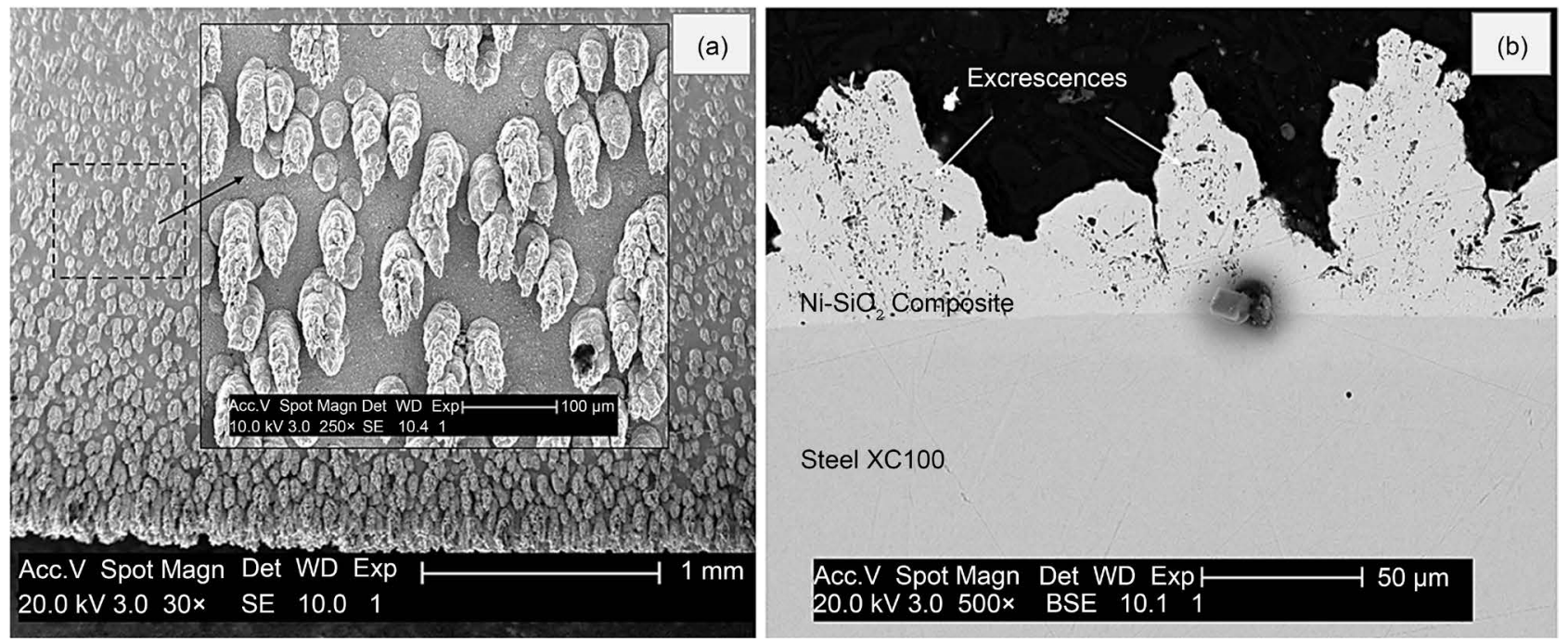

Figure 3. Morphology (a) and cross-sectional view (b) of the excrescences formed by the composite coating $\mathrm{Ni}_{-} \mathrm{SiO}_{2}$ in the draining at the surface of the electrode in LHF $(R e=4244)$.
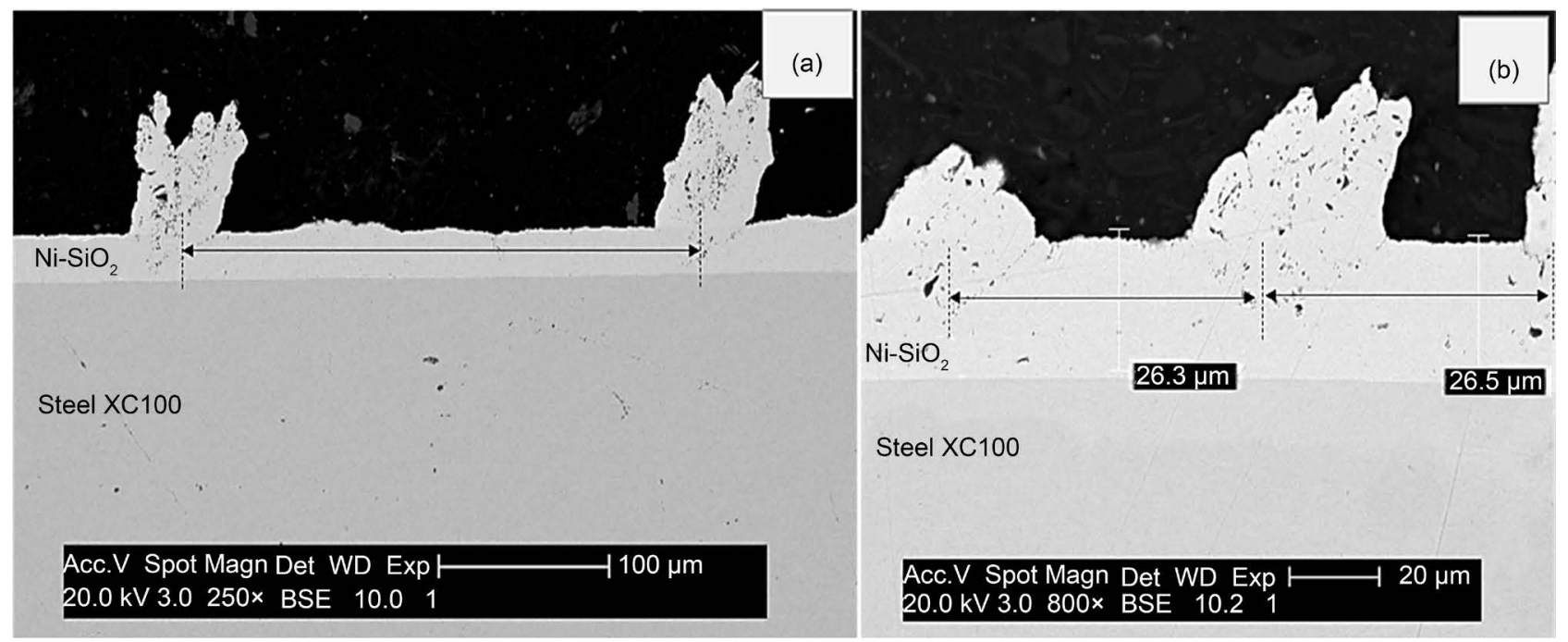
$\mathrm{Ni}-\mathrm{SiO}_{2}$

Steel $\mathrm{XC} 100$

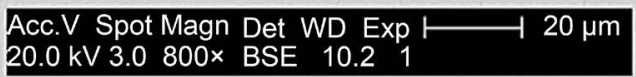

Figure 4. SEM of the cross-sections of excrescences of $\mathrm{Ni}_{-} \mathrm{SiO}_{2}$ developed for (a) $R e=1570$ (LLF) and (b) $R e=5570$ (LHF); $d=5$ $\mathrm{mm}$.

the surface and is then aspirated by the peristaltic pump. The renewal of the jet impinging on the cathode implies that the suspension flows in a wave-like movement characterized by certain amplitude and a wavelength $\lambda$. The value of $\lambda$ corresponds to the distance between two consecutives excrescences. It was observed that $\lambda$ decreases when the flow rate increases, that is when the Reynolds number increases.

Due to this undulation at the surface of the cathode, the electrolyte flow forms particles-rich pockets corresponding to the maximum amplitude of the excrescences. On the opposite, minimum amplitude valleys, poor in particles also form. A sketch of the particle distribution according to the wave-like flow on the cathode is presented in Figure 5. This distribution, maintained during the metal nucleation, favors the formation of sites rich in particles here called excrescences. 


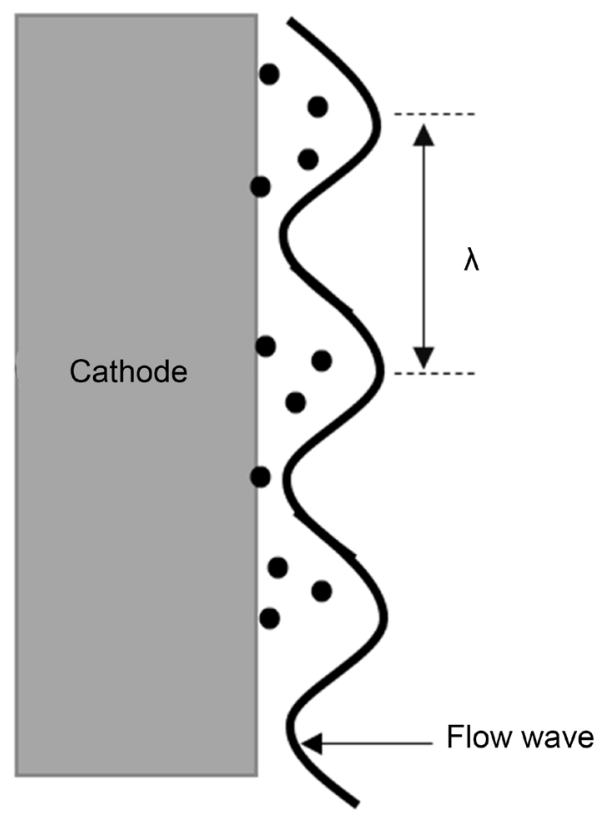

Figure 5. Sketch of the wave-like flow on the cathode at the origin of the formation of the excrescences.

By analogy to the wave energy aspect, the variation of spacing between the excrescences for different Reynold numbers clearly confirms the energy aspect of these flows. Indeed, the flow energy is inversely proportional to the wavelength. Thus, for high flow rate, so high energy, the wavelength is shorter. Here the shorter wavelength $\lambda=33 \mu \mathrm{m}$ is related to the higher Reynolds number that is to say for higher flow rate.

\section{2. $\mathrm{SiO}_{2}$ Particles Density and Percentage Embedded in Composite Coating}

\subsubsection{Effect of the Flow Regime}

The density of silica particles in composite coatings at a distance $d$ corresponding to $5 \mathrm{~mm}$ for three Reynolds numbers each corresponding to a hydrodynamic regime is exhibited in Figure 6.

The density of silica particles in composite coatings at a distance $d$ corresponding to $5 \mathrm{~mm}$ for three Reynolds numbers, each corresponding to a hydrodynamic regime is exhibited in Figure 6. The silica particles distribution and the excrescences size are the most regular, homogenous and uniform for the coating deposited in the laminar LLF regime, i.e. at $R e=1570$. Moreover, for the samples prepared in high flow conditions, the amount of excrescences is the highest at the surface of the codeposit and their size is larger. This corroborates the mechanism of excrescence formation proposed above. In fact, the most numerous the excrescences are, the smallest the distance between them or the wavelength is.

As it can be observed in Figure 6(b) and Figure 6(c), the coatings prepared in the transitory disturbance and laminar high flow modes present an area which is less dense in particles (upper right corners). It is certainly related to the turbulence 

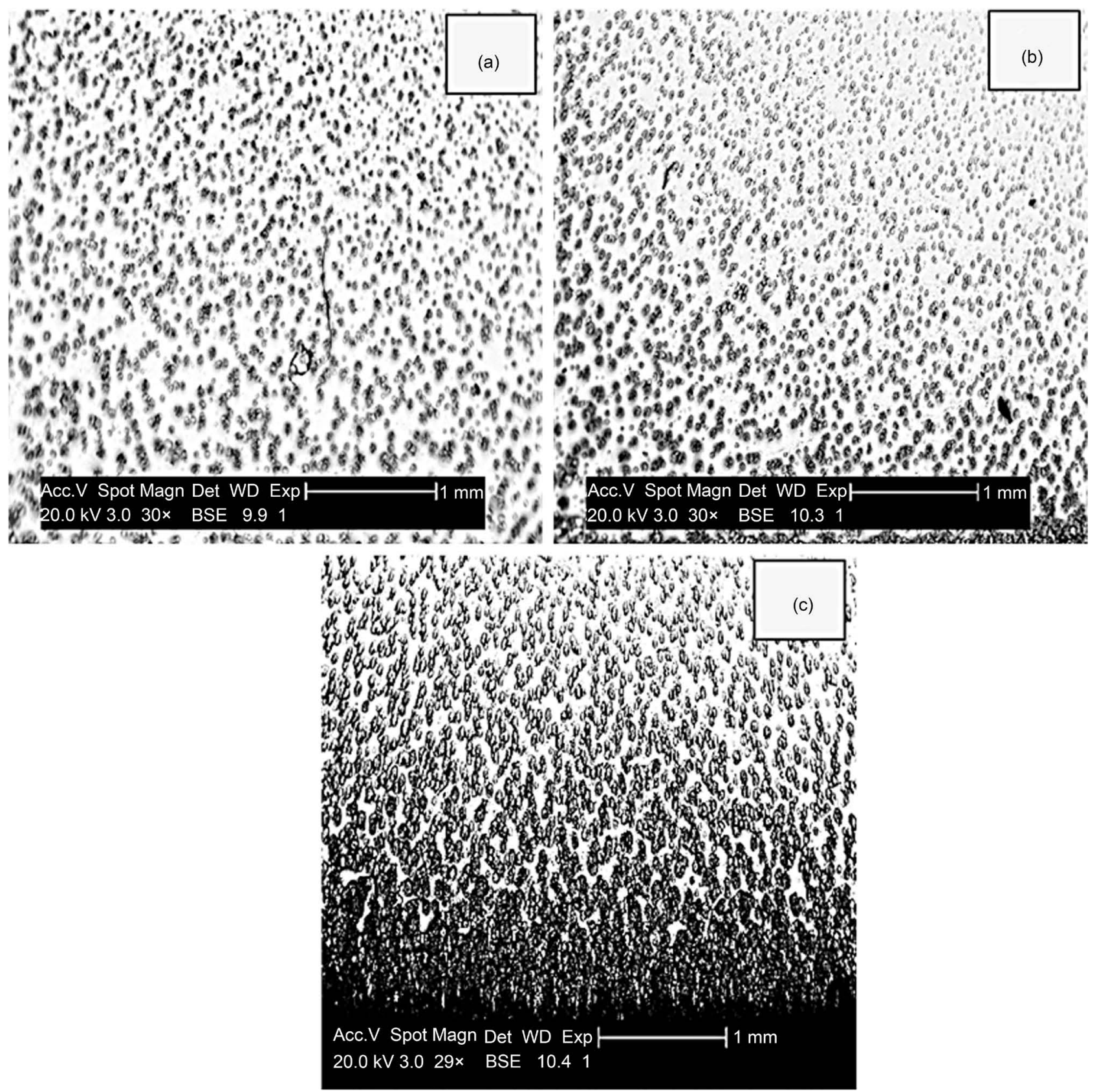

Figure 6. Silica distribution in draining flow area as a function of Reynolds number. $d=5 \mathrm{~mm}$. (a) $\operatorname{Re}=1570$ (LLF); (b) $R e=3714$ (Transitory Disturbance); (c) $R e=5970$ (LHF).

of the regime. Indeed, as the system is closed, a higher level of turbulence induces an increase of the drainage velocity $V_{d r}$. In addition, the electric field lines establishment is also disturbed by the flow turbulences. One of the consequences is that the duration of the stay of the particles in the stagnation zone decreases and so does the probability of particle embedment. However, the lower zone of the cathode still remains in the electrolyte where the electric field lines favor the load of silica in the nickel matrix. In this zone, the percentage of silica particles loaded increases. As the flow velocity rises and reaches the LHF mode, the amount of particles in the lower zone increases as testified by the distribution of 
black spots on the SEM images.

\subsubsection{Effect of $d$ and the Flow Regime}

In LLF or LHF modes, for the Reynolds numbers studied, increasing $d$ causes a non-uniform distribution of the silica particles (Figure 7). The excrescences size also raises with the hydrodynamic parameters.

The lower density of particles in ECCs deposited at a nozzle-to-cathode distance of $15 \mathrm{~mm}$ is due to a particles-load loss of the impinging jet. Out of the nozzle, particles undergo gravity. The volume of suspension which spreads on the cathode surface is therefore less concentrated in particles. Thus, the closest the nozzle is to the cathode, the more homogeneous and dense the ECC is.
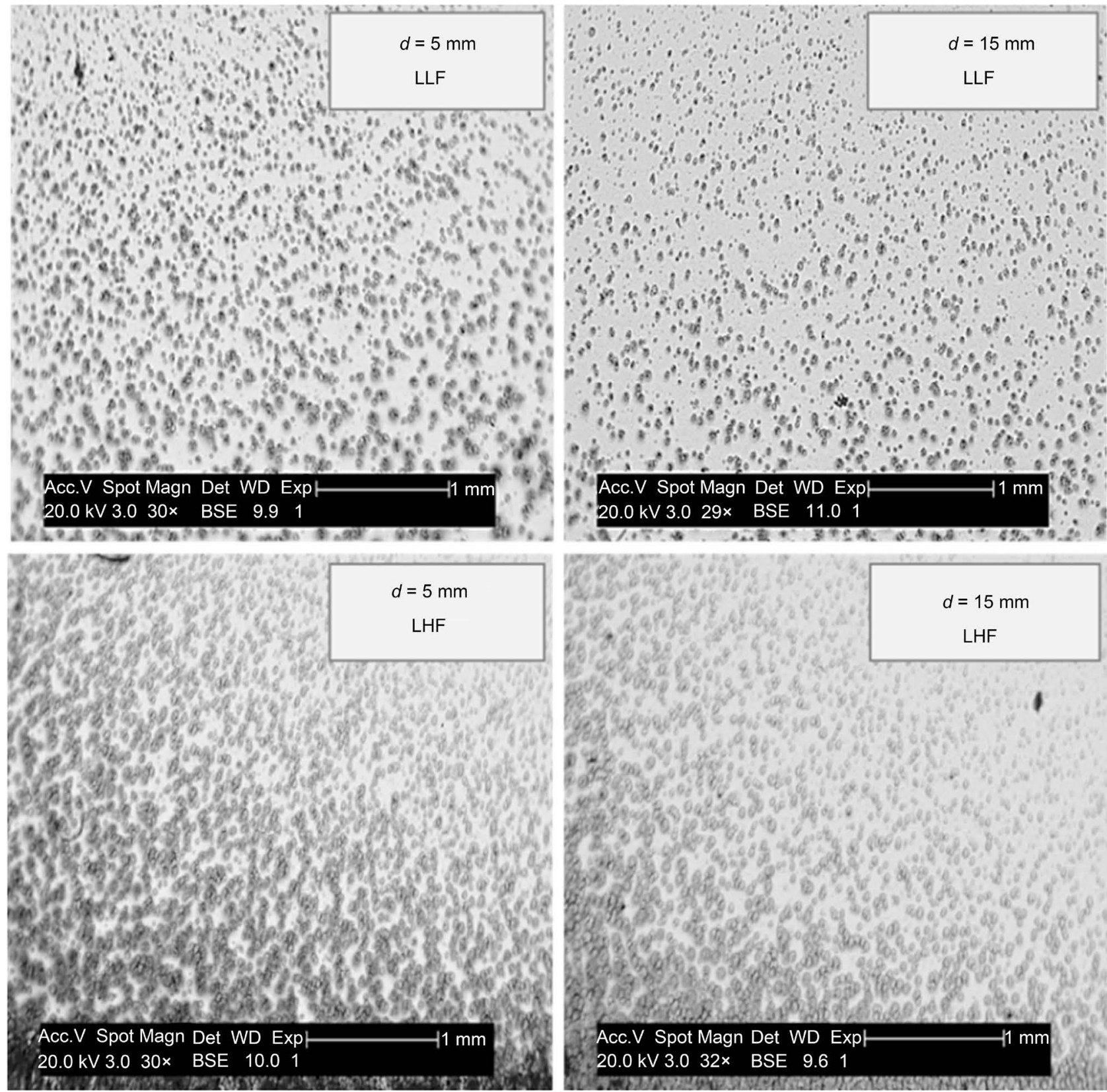

Figure 7. SEM images of silica distribution onto $\mathrm{Ni}_{-} \mathrm{SiO}_{2}$ surface as a function of $d$ in $\mathrm{LLF}(R e=1570)$ and in $\mathrm{LHF}(\operatorname{Re}=5570)$. 
The percentages of silica particles loaded in nickel/silica composite coatings determined on the basis of an EDS analysis are summarized in Table 2.

Analysis of the data collected shows that the weight percentages of embedded particles, for a constant $d$, decreases with increasing the Reynolds number. For example, the silica amount decreases from $4.43 \pm 0.09 \mathrm{wt} \%$ to $3.72 \pm 0.15 \mathrm{wt} \%$ with increasing Reynolds number from 1570, in LLF mode, to 2270 in LHF mode. During the jet, particles reach the surface with a horizontal velocity $V_{h}$ which gives them a momentum $p$ according to Equation (1):

$$
p=m V_{h} \text {. }
$$

with $m$ being the mass of silica particles.

While reaching the surface, these particles are prone to either elastic or inelastic collisions. For a same distance $d$ and low Reynolds numbers, i.e. low flow velocities, the probability of inelastic collisions is high. In this case, particles remain longer at the sample surface and can be embedded. However, increasing the Reynolds number increases the probability of particles to undergo elastic collisions. They move away from the substrate and the silica uptake in the coating decreases.

Besides, the proximity between the nozzle and the surface of the metallic sheet is beneficial to the particles loading. In fact, the weight percentage of $\mathrm{SiO}_{2}$ decreases from $4.43 \pm 0.09$ to $3.60 \pm 0.06$ when the nozzle-to-cathode $d$ increases from 5 to $15 \mathrm{~mm}$. Considering the conical trunk defined between the nozzle surface and the basis surface positioned at the cathode, it is obvious that the suspension spreads on a larger basis surface when $d$ increases. In these conditions, the jet is less focalized and, as a consequence, less particles reach the surface of the cathode and the particle content in the ECC decreases, as experimentally observed. Nevertheless, in view of the silica weight percentages, the IJC here used herein has improved very significantly the amount of silica uptake in the coating, compared to previous reported works [28] [29]. The very high surface hydrophilicity of silica particles due to their chemical features has been overcome by a simple physical approach.

The results prove that the amount of silica particles embedded in nickel matrix can be controlled by the hydrodynamics regardless of their surface state.

\section{Conclusions}

In this paper, the effects of hydrodynamics parameters such as the flow regime,

Table 2. Amount in weight percent (wt\%) of silica particles embedded as a function of $d$ and the flow regimes.

\begin{tabular}{cccc}
\hline & \multicolumn{3}{c}{$\mathrm{SiO}_{2} \mathrm{wt} \%$} \\
\hline Regimes & $\operatorname{Re}$ & $d=5 \mathrm{~mm}$ & $d=15 \mathrm{~mm}$ \\
\hline LLF & 1570 & $4.43 \pm 0.09$ & $3.60 \pm 0.06$ \\
Perturbed & 3714 & $4.30 \pm 0.07$ & $3.43 \pm 0.19$ \\
LHF & 5570 & $3.72 \pm 0.15$ & $3.17 \pm 0.20$ \\
\hline
\end{tabular}


the Reynolds number as well as the nozzle-to-cathode distance $d$ on the effectiveness of particle embedment into a nickel/silica composite coating prepared by electrodeposition in an IJC setup were studied. It showed that the embedded nickel grain size increased with the flow rate of the electrolyte. The microstructures of the composite present excrescences developed due to the wave-like flow of the electrolyte over the cathode surface. The spacing between these excrescences decreases with the flow rate.

The results obtained indicate that the laminar low flow regime and a distance of $5 \mathrm{~mm}$ between the nozzle and the cathode are optimal amongst the tested conditions to improve the amount of silica particles in the composite $\mathrm{Ni}_{-} \mathrm{SiO}_{2}$. In these conditions, $4.43 \pm 0.09 \mathrm{wt} \%$ of silica particles were successfully embedded in the coating, which was expecting to significantly improve its mechanical properties.

\section{Acknowledgements}

This work was supported by Swiss Government through the "Swiss Government Excellence Scholarship" (No. 2012.067/Côte d'Ivoire/OP).

\section{References}

[1] Fink, C.G. and Prince, J.D. (1928) The Codeposition of Copper and Graphite. Transactions of the American Electrochemical Society, 54, 315-321.

[2] Metzer, W., Ott, R., Laux, G. and Harst, H. (1970) Die Ab scheidung von Nickeldispersionsschichten. Galvanotechnik, 61, 998.

[3] Wang, S. and Wei, W.J. (2003) Characterization of Electroplated $\mathrm{Ni} / \mathrm{SiC}$ and $\mathrm{Ni}$ $/ \mathrm{Al}_{2} \mathrm{O}_{3}$ Composite Coatings Bearing Nanoparticles. Journal of Materials Research, 18, 1566-1574. https://doi.org/10.1557/JMR.2003.0216

[4] Özkan, S., Hapçı, G., Orhan, G. and Kazmanlı, K. (2013) Electrodeposited Ni/SiC Nanocomposite Coatings and Evaluation of Wear and Corrosion Properties. Surface and Coatings Technology, 232, 734-741. https://doi.org/10.1016/j.surfcoat.2013.06.089

[5] Ben Temam, H., Zeroual, L., Chala, A., Rahmane, S. and Nouveau, C. (2007) Microhardness and Corrosion Behavior of Ni-SiC Electrodeposited Coatings. Plasma Processes and Polymers, 4, S618-S621. https://doi.org/10.1002/ppap.200731417

[6] Vaezi, M.R., Sadrnezhaad, S.K. and Nikzad, L. (2008) Electrodeposition of Ni-SiC Nano-Composite Coatings and Evaluation of Wear and Corrosion Resistance and Electroplating Characteristics. Colloids and Surfaces A: Physicochemical and Engineering Aspects, 315, 178. https://doi.org/10.1016/j.colsurfa.2007.07.027

[7] Maurin, G. and Lavanant, A. (1995) Electrodeposition of Nickel/Silicon Carbide Composite Coatings on a Rotating Disc Electrode. Journal of Applied Electrochemistry, 25, 1113-1121. https://doi.org/10.1007/BF00242538

[8] Rudnik, E., Burzyńska, L., Dolasiński, Ł. and Misiak, M. (2010) Electrodeposition of Nickel/SiC Composites in the Presence of Cetyltrimethylammonium Bromide. Applied Surface Science, 256, 7414-7420. https://doi.org/10.1016/j.apsusc.2010.05.082

[9] Popczyk, M. (2008) The Influence of Molybdenum and Silicon on Activity of Ni + W Composite Coatings in the Hydrogen Evolution Reaction. Surface and Interface Analysis, 40, 246-249. https://doi.org/10.1002/sia.2696

[10] Chen, L., Wang, L., Zeng, Z. and Xu, T. (2006) Influence of Pulse Frequency on the 
Microstructure and Wear Resistance of Electrodeposited Ni- $\mathrm{Al}_{2} \mathrm{O}_{3}$ Composite Coatings. Surface and Coatings Technology, 201, 599-605.

https://doi.org/10.1016/j.surfcoat.2005.12.008

[11] Beltowska-Lehman, E., Goral, A. and Indyka, P. (2011) Electrodeposition and Characterization of $\mathrm{Ni} / \mathrm{Al}_{2} \mathrm{O}_{3}$ Nanocomposite Coatings. Archives of Metallurgy and Materials, 56, 919-931. https://doi.org/10.2478/v10172-011-0101-1

[12] Kasturibai, S. and Kalaignan, G.P. (2012) Physical and Electrochemical Characterizations of $\mathrm{Ni}_{-} \mathrm{SiO}_{2}$ Nanocomposite Coatings. Ionics, 19, 763-770. https://doi.org/10.1007/s11581-012-0810-0

[13] Terzieva, V., Fransaer, J. and Celis, J.P. (2000) Codeposition of Hydrophilic and Hydrophobic Silica with Copper from Acid Copper Sulfate Baths. Journal of the Electrochemical Society, 147, 198-202. https://doi.org/10.1149/1.1393174

[14] Berçot, P., Peña-Muñoz, E. and Pagetti, J. (2002) Electrolytic Composite Ni-PTFE Coatings: An Adaptation of Guglielmi's Model for the Phenomena of Incorporation. Surface and Coatings Technology, 157, 282-289.

https://doi.org/10.1016/S0257-8972(02)00180-9

[15] Garcia, I., Fransaer, J. and Celis, J.P. (2001) Electrodeposition and Sliding Wear Resistance of Nickel Composite Coatings Containing Micron and Submicron SiC Particles. Surface and Coatings Technology, 148, 171-178.

https://doi.org/10.1016/S0257-8972(01)01336-6

[16] Lee, H.-K., Lee, H.-Y. and Jeon, J.-M. (2007) Codeposition of Micro- and NanoSized SiC Particles in the Nickel Matrix Composite Coatings Obtained by Electroplating. Surface and Coatings Technology, 201, 4711-4717. https://doi.org/10.1016/j.surfcoat.2006.10.004

[17] Pavlatou, E.A., Stroumbouli, M., Gyftou, P. and Spyrellis, N. (2006) Hardening Effect Induced by Incorporation of SiC Particles in Nickel Electrodeposits. Journal of Applied Electrochemistry, 36, 385-394.

https://doi.org/10.1007/s10800-005-9082-y

[18] Guglielmi, N. (1972) Kinetics of the Deposition of Inert Particles from Electrolytic Baths. Journal of the Electrochemical Society, 119, 1009-1012. https://doi.org/10.1149/1.2404383

[19] Low, C.T.J., Wills, R.G.A. and Walsh, F.C. (2006) Electrodeposition of Composite Coatings Containing Nanoparticles in a Metal Deposit. Surface and Coatings Technology, 201, 371-383. https://doi.org/10.1016/j.surfcoat.2005.11.123

[20] Celis, J.P., Roos, J.R. and Buelens, C. (1987) A Mathematical Model for the Electrolytic Codeposition of Particles with a Metallic Matrix. Journal of the Electrochemical Society, 134, 1402-1408. https://doi.org/10.1149/1.2100680

[21] Yang, Y. and Cheng, Y.F. (2013) Mechanistic Aspects of Electrodeposition of NiCo-SiC Composite Nano-Coating on Carbon Steel. Electrochimica Acta, 109, 638644. https://doi.org/10.1016/j.electacta.2013.07.106

[22] Celis, J.P. and Roos, J.R. (1977) Kinetics of the Deposition of Alumina Particles from Copper Sulfate Plating Baths. Journal of the Electrochemical Society, 124, 1508-1511. https://doi.org/10.1149/1.2133102

[23] Nowak, P., Socha, R.P., Kaisheva, M., Celis, J.P. and Stoinov, Z. (2000) Electrochemical Investigation of the Codeposition of $\mathrm{SiC}$ and $\mathrm{SiO}_{2}$ Particles with Nickel. Journal of Applied Electrochemistry, 30, 429-437. https://doi.org/10.1023/A:1003979117146

[24] Zhuravlev, L.T. (2000) The Surface Chemistry of Amorphous Silica. Zhuravlev Model. Colloids and Surfaces A: Physicochemical and Engineering Aspects, 173, 1-38. https://doi.org/10.1016/S0927-7757(00)00556-2 
[25] Kobayashi, H. (1993) Surface Treatment of Fumed Silica with Oligodimethylsiloxane- $\alpha, \omega$-Diol. Journal of Colloid and Interface Science, 156, 294-295. https://doi.org/10.1006/jcis.1993.1114

[26] Abro, D.M.K., Dable, P., Cortez-Salazar, F., Amstutz, V., Kwa-Koffi, E.K. and Girault, H. (2016) Design and Characterization of a Horizontal Double Impinging Jet Cell: Determination of Flow Modes at the Surface of a Flat Electrode. Journal of Materials Science and Chemical Engineering, 4, 18-28.

https://doi.org/10.4236/msce.2016.48003

[27] Ciubotariu, A., Benea, L., Lakatos-Varsanyi, M. and Dragan, V. (2008) Electrochemical Impedance Spectroscopy and Corrosion Behaviour of $\mathrm{Al}_{2} \mathrm{O}_{3}$-Ni Nano Composite Coatings. Electrochimica Acta, 53, 4557-4563.

https://doi.org/10.1016/j.electacta.2008.01.020

[28] Socha, R.P., Nowak, P., Laajalehto, K. and Väyrynen, J. (2004) Particle-Electrode Surface Interaction during Nickel Electrodeposition from Suspensions Containing $\mathrm{SiC}$ and $\mathrm{SiO}_{2}$ Particles. Colloids and Surfaces A: Physicochemical and Engineering Aspects, 235, 45-55. https://doi.org/10.1016/j.colsurfa.2004.01.011

[29] Miyamoto, H., Ueda, K. and Uenoya, T. (2010) Mechanical Properties of Electrode-

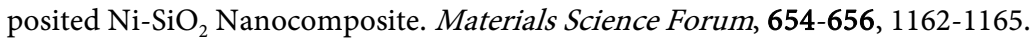
https://doi.org/10.4028/www.scientific.net/MSF.654-656.1162

Submit or recommend next manuscript to SCIRP and we will provide best service for you:

Accepting pre-submission inquiries through Email, Facebook, LinkedIn, Twitter, etc. A wide selection of journals (inclusive of 9 subjects, more than 200 journals)

Providing 24-hour high-quality service

User-friendly online submission system

Fair and swift peer-review system

Efficient typesetting and proofreading procedure

Display of the result of downloads and visits, as well as the number of cited articles

Maximum dissemination of your research work

Submit your manuscript at: http://papersubmission.scirp.org/

Or contact msce@scirp.org 